\title{
Water scarcity and poverty: The lasting impact of a maintenance campaign at South African schools across the affluence divide
}

\author{
M. J. Booysen^, S. Gerber \\ * Department Electrical and Electronic Engineering, Stellenbosch University, \\ Private Bag X1, Stellenbosch, 7600, South Africa \\ (E-mail:mjbooysen@sun.ac.za ; stefan.gerber@live.co.za) \\ ${ }^{\wedge}$ Corresponding author
}

\begin{abstract}
Water features prominently in discussions on sustainability. The recent Cape Town "Day Zero" drought heightened fears about global cities running dry as the climate changes. During that crisis a campaign was launched to save water at schools, consisting of a basic maintenance campaign and a behavioural campaign. The former was limited to easy fixes, and the latter comprised an information campaign and an information and competition campaign. The impacts of these were assessed immediately after the interventions. This paper revisits the maintenance results by assessing the difference in responses according to affluence levels of the schools, and by evaluating the impacts a year after the campaigns. We find that the poorer schools were not able to sustain the maintenance gains, especially at the primary schools.
\end{abstract}

\section{Highlights}

- The impact of a maintenance campaign at Cape Town schools during the "Day Zero" drought was assessed.

- Short term impact and long term impact - a year later, after the drought are evaluated.

- School affluence is evaluated as a factor in the effectiveness of the maintenance campaign.

- Short-term impact was greater at poor schools, but gains diminished a year later.

- Affluent schools benefitted from a lower base in the short term, and maintained gains better.

\section{Keywords}

water conservation; smart water meters; school water system maintenance; socioeconomic comparison 


\section{INTRODUCTION}

By 2025 half of the world's population will be living in water-stressed areas (WHO, 2019). As climate change becomes more prevalent due to increasing global temperatures, rainfall is expected to become progressively more extreme, leading to a rise in both droughts and floods globally. This attributed to the "El Nino" weather pattern seen in South Africa in 2015, and which culminated in the worst prolonged drought the country has experienced since at least the 1940s (Baudoin et al., 2017). Average dam levels decreased from $93 \%$ in early 2014 to a low of $48 \%$ in November 2016. But water supply in South Africa is unevenly distributed due to changes in climate, invasive plant species and rapid urbanisation in the country's cities (Enqvist and Ziervogel, 2019).

Cape Town was the worst affected major city, with water levels of freshwater supplying dams nearing $15 \%$. In early 2018 , the city was declared a disaster area with a countdown towards a "Day Zero". Authorities and citizens feared a complete shutdown of all water resources. This would have required manual collection of daily water rations (Enqvist and Ziervogel, 2019). This event brought water security and management into sharp focus in South Africa, leading many to question whether the drought was the main cause of water scarcity in the city and the rest of the country. The drought was simply a catalyst highlighting many underlying vulnerabilities in South Africa's water system and the challenges it faces to ensure water security for its entire population (Donnenfeld et al., 2018).

Water is indispensable for life: the need to maintain its availability is vital. Thus, there has been a recent surge in new studies and developments aimed at improving water management and security (Bougadis et al., 2005; Ghiassi et al., 2008; Adamowski et al., 2012; Ren and Li, 2016).

However, limited research has been done in the non-residential and educational sectors even though these sectors can be large users of freshwater resources (Booysen et al., 2019b). In particular, schools were a primary concern during Cape Town's "Day Zero" campaign - not only because they would have to close once the water ran out and thereby affect education, but also due to their excessive usage volumes (Gallego Sanchez-Torija et al., 2017).

According to the South African School's Act of 1996, immovable funds should always be available in case of emergency and routine repairs. However, due to mismanagement of government funds many schools are left with extremely constrained budgets (Spaull, 2019; WCG, 2020; Samuels et al., 2020). These financial constraints make it exceedingly difficult for schools to maintain their water delivery infrastructure. As a result, they generally lose large amounts of water each month (Booysen et al., 2019a). Moreover, schools are generally billed on a month to month basis using the recorded usages on their municipal water meter. Not only do these bills take months to arrive, but they are often paid by the central education department, worsening an already unfavourable situation. 


\section{RELATED RESEARCH}

This section analyses recently published studies working to combat poor water management in schools. As the need for more stringent water management and usage guidelines grows within waterscarce countries, conservation efforts within schools have evolved as well. A recent study by Bueno (2019) implemented various sustainability measures within schools in the Philippines to reduce energy and water usage. The study found that there was a large increase in wastage in older schools built before the introduction of sustainability measures. Favourable savings were achieved through both technological and behavioural interventions. The study concluded that the ability to minimise water use, waste and loss over longer periods is heavily dependent on constant reinforcement measures. These include technical and educational assistance programs to educate teachers and students adequately.

Tarbet et al. (2006) examined the conditions of water management and infrastructure within schools in Windhoek, Namibia to reduce usage. The study revealed that the most cost-effective method for reducing water usage within schools was educating maintenance workers to perform regular infrastructure assessments. It was found that investments in tap, toilet and shower-head repairs repaid themselves within 9, 85 and 33 days, respectively. Additional measures include educating the first and eighth-grade students in compulsory sustainability courses, holding regular awareness campaigns, and incentivising schools to reduce their water usage by refunding them a percentage of their monthly savings to be better spent on improving the quality of education delivered within the school.

Middlestadt et al. (2010) led a behavioural intervention study in Jordan focused on educating students to make more environmentally responsible decisions. A group of experimental and control students were compared, with the experimental group performing better in all evaluations. The study concluded that short-term behavioural changes precede attitudinal changes. Nevertheless, some students may require evidence of progress using performance metrics to sustain their environmentally-friendly behaviour.

Xiong et al. (2016) investigated the effectiveness of a compulsory water-conservation education program for all grade 9 students in China's major cities. A survey from Guangzhou determined that although $95 \%$ of students enrolled in the course were aware of the need for water conservation, only $19 \%$ were willing to actively use water more responsibly. It was also determined that student behaviour improves significantly with age: $14 \%, 24 \%$ and $56 \%$ of intervened students reduced their total water usage from primary schools, high schools and universities, respectively. 
These studies have highlighted many of the challenges schools face, not only in terms of maintenance and financial difficulties but also the need to actively enforce behavioural interventions when working with students.

Within the South African context, there are many similar and more pressing issues. Most notably the recent drought in Cape Town. The South African education system is ill-equipped and lacks the necessary financial resources needed to effectively manage such events (Xaba, 2012; Spaull, 2019; WCG, 2020). The School's Act of 1995 was created to combat the wealth gap within schools and to ensure effective management of financial resources and much-needed maintenance to infrastructure. But, these policies were never properly initiated, leading to mismanagement of public funds and a greater educational gap between the richer and poorer schools in the country (Lomofsky and Lazarus, 2001; Engelbrecht and Harding, 2008; Booysen et al., 2019b). A study by van der Berg et al. (2011) reported on how the low quality of education provided in schools within disadvantaged communities can lead to exclusion and marginalisation, limiting the prospects of learners from a young age. In $2006,49 \%$ of education spending reached the poorest $40 \%$ of households (van der Berg, 2009; van der Berg et al., 2011). In 2017 this had improved to 54\% (McLaren, 2017). However, after personnel spending and conditional grants, only $10 \%$ to $20 \%$ of the budget remained for non-personnel expenses, which includes textbooks, laboratory equipment, stationery, school maintenance and utility costs.

In 2008 a call was made to amend the national education policy and to prioritise maintenance spending for schools with many reporting that the allocated amount of R209 million was insufficient for all schools in the Western Cape. According to a 2020 report, this allocation has now increased to R636 million for maintenance alone. However, 2019 reports have also stated that R300 million of the allocated maintenance budget had to be diverted for drought mitigation measures (WCED, 2019). The report also acknowledges that there is a large backlog of maintenance still needed to be done and that many of the staff employed by schools are not sufficiently skilled to perform the maintenance effectively.

Water supply within South African schools is unreliable. In 2015 the department of Basic Education released a report indicating that $3 \%$ of schools had no access to water, and more than $25 \%$ of schools had an unreliable water supply with more than 4500 schools relying on pit latrines (WCED, 2019). Financial constraints coupled with governmental warnings of school closures during the water crisis due to insufficiently trained staff to fix leaks should they occur makes it clear: the disconnect between the educational and political spheres in the country is immense.

The discussed studies (Tarbet et al., 2006; Middlestadt et al., 2010; Xiong et al., 2016; Bueno, 2019) investigated the effects of technical and behavioural interventions within schools in developing 


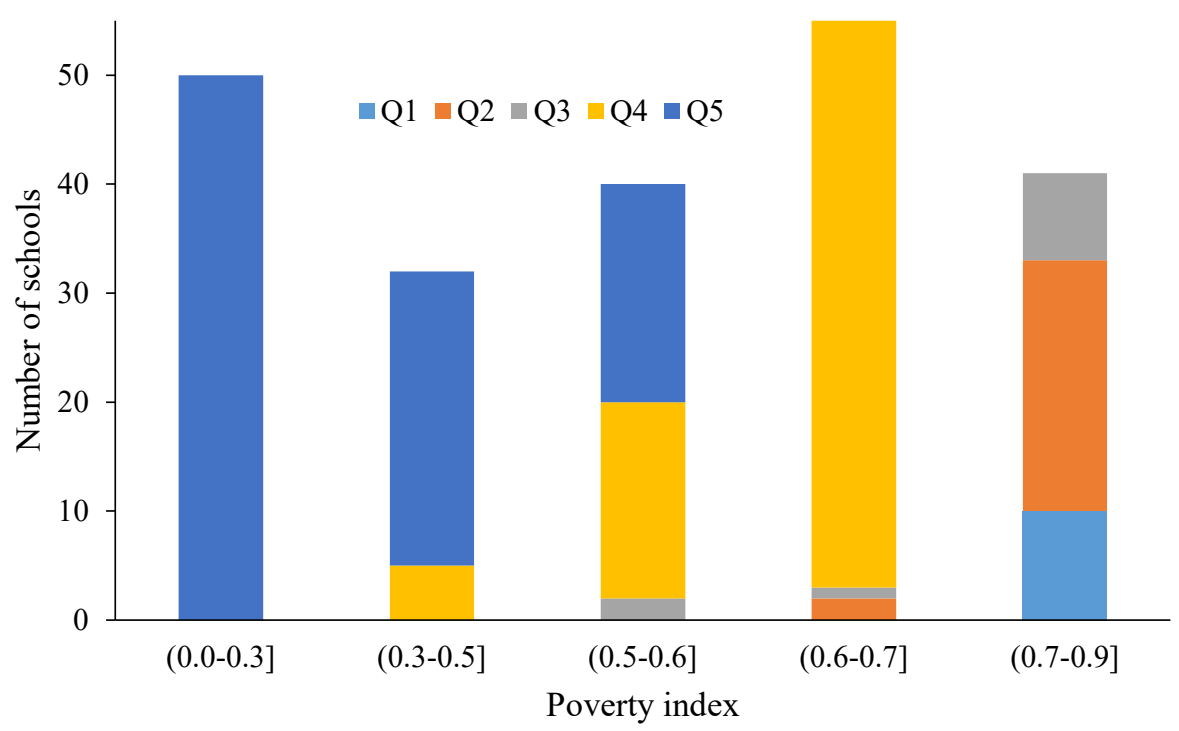

Figure 1: Distribution of schools from different quintiles in relation to the Western Cape poverty index.

nations with water-scarce areas. These studies presented favourable findings and provided recommendations on how to improve sustainability measures in the long term. But cognisance has to be taken of the South African context. South Africa's education system is spread over all socioeconomic groups: each requires to a varying degree government intervention through funding and maintenance schemes. The ability to quantify the effects of behavioural and technical interventions for schools from different socio-economic groups will empower decision makers to make better data driven decisions. This will allow them to allocate funds more effectively as well as to improve the responsiveness of their maintenance programs.

Since the 2008 amendments to the National Education Policy several studies have evaluated watersaving interventions, and water awareness campaigns at small samples of schools (Still and Bhagwan, 2008). Further studies by Nhlapo (2009) and Xaba (2012) investigated the maintenance needs of schools in Gauteng, concluding that current maintenance plans were reactive rather than proactive. Moreover, due to a lack of funds maintenance was performed by gardeners and groundsmen rather than qualified technicians. This serves to highlight the need to establish an effective school maintenance policy.

Recent studies performed the most comprehensive analysis of water usage and management within schools in the Western Cape (Visser et al., 2021; Booysen et al., 2019a, b). This included investigating socio-economic effects, behavioural interventions and technical interventions. These studies provided favourable results and recommendations, equipping local policymakers with the knowledge to implement better water management policies. However, none of these and other discussed studies evaluated the long-term viability of their interventions, and none evaluated the impact of school affluence on the interventions. 
There has been a recent surge in the deployment of smart water meters in South Africa, albeit from a very low base. Accurate water usage data is essential for specifying a building's water demand. In South Africa, most buildings receive their water usage monthly from their municipal water meter. This oversimplified metric is unable either to characterise a building's demand or to determine quickly if a leak has occurred.

The most comprehensive study by Booysen et al. (2019a) explored usage data from 156 schools over 30 days in 2017. The behavioural study performed by Visser et al. (2021) evaluated 105 schools over a period from February 2018 to October 2018.

\section{CONTRIBUTION}

This paper describes the medium- and long-term effects of a campaign that was run at schools during 2017 and 2018 in the run-up to "Day Zero" in Cape Town. The campaign had a behavioural and maintenance component (Booysen et al., 2019b; Visser et al., 2021). The objective of this study is to evaluate the long-term effects of technological intervention within schools in the Western Cape and to better define the effects of poverty on a school's water usage. In addition to providing an understanding of the long-term impacts of these interventions at schools - something not known at present - these results will assist with the decision making process necessary to amend and improve current water-management and conservation policies. This study will explore usage data of 270 schools from October 2017 until August 2019.

\section{WATER USAGE: A LONG TERM ANALYSIS}

\section{Data exploration}

Using the available dataset of 270 schools and taking into account the observations made during previous studies, several features were identified to better describe the data for analysis based on the following factors: (1) It was observed that some schools are used as church buildings on Sundays. (2) More affluent schools have sporting activities on Saturdays and during weekday evenings. (3) Some schools have learners and staff who stay in hostels and residences on the school property. (4) Some poorer schools have adult education and community programs during the evenings. (5) Some more affluent schools water their sports fields after 23:00 to avoid water evaporating unnecessarily.

As with the previous studies it is especially important to be able to distinguish water wastage from general usage when looking at school usage profiles. For example, some schools might consider a large nightly water usage as leakage, but to more affluent schools it may just be the periodic wetting of sports grounds.

\section{Overview of schools in dataset}


The large smart meter dataset evaluated during this study encompasses all types of schools present in the Western Cape and the rest of South Africa. The National Norms and Standards for School Funding (NNSSF) established how much government funding each non-private school would receive based on their quintile level. A quintile level between 1 and 5 is assigned to each school in the country with the poorest $20 \%$ of students attending quintile 1 schools and the most affluent $20 \%$ of students attending quintile 5 schools. These categories were established on a national level. Thus, certain provinces will have more wealthy students, and as such, more quintile 5 schools than other provinces. The Western Cape is one of the most prosperous provinces and has the largest relative percentage of quintile 5 schools.

In addition to the quintile classification, schools are grouped into fee paying or no fee paying schools, as well as Section 20 and Section 21 schools. Fee paying schools charge their students fees to raise their necessary funding. No fee schools do not charge learners school fees. Moreover, Section 21 schools are responsible to pay for their own upgrades, school materials, utility bills and maintenance Samuels et al. (2020). These schools are allocated funding by the government, however, from observations made during previous studies this funding was found to be insufficient (Booysen et al., 2019a). In contrast, Section 20 schools are not charged monthly utility costs and are not responsible for their own maintenance. This service for these schools is provided directly by the government. Most no fee and Section 20 schools fall within quintiles 1 to 3 , receiving a combined $80 \%$ of the government's educational expenditure distributed to the poorest $60 \%$ of learners (McLaren, 2017).

This study expands on the socio-economic view of the various groups of schools defined above, by introducing a poverty index scaler. The value, ranging from 0 to 1 , is defined on a provincial basis rather than the quintile index's national basis. The number is calculated from two equally weighted factors: (1) The physical condition, facilities and crowding of the school, and (2) the relative poverty of the community surrounding the school compared to the rest of the province. An overview of the

Table 1: Breakdown of schools in the complete dataset.

\begin{tabular}{clccccc} 
Quintile & Phase & Total & Section 20 & Section S21 & No-fee & Fee paying \\
\hline $\mathbf{1}$ & Primary & 8 & 2 & 6 & 8 & 0 \\
& High & 2 & 1 & 1 & 2 & 0 \\
$\mathbf{2}$ & Primary & 26 & 12 & 14 & 26 & 0 \\
& High & 6 & 3 & 3 & 6 & 0 \\
$\mathbf{3}$ & Primary & 18 & 5 & 13 & 18 & 0 \\
& High & 12 & 4 & 8 & 12 & 0 \\
$\mathbf{4}$ & Primary & 56 & 14 & 42 & 34 & 22 \\
& High & 25 & 9 & 16 & 6 & 19 \\
$\mathbf{5}$ & Primary & 68 & 6 & 62 & 8 & 60 \\
& High & 49 & 10 & 39 & 2 & 47 \\
\hline Total & & 270 & 66 & 204 & 122 & 148
\end{tabular}

evaluated schools is presented in Figure 1, indicating that the quintile classification by itself may be 
insufficient to describe the socio-economic state of a school.

Table 1 provides a breakdown of the schools in the dataset. Most schools were classified as quintile 4 and 5 (73.3\%). Most schools were self-governed (75.7\%) and required students to pay fees (54.8\%).

\section{Overview of interventions performed at schools in the dataset}

Booysen et al. (2019b) describes the maintenance project, which was launched during the "Day Zero" water savings campaign. A maintenance drive was performed, and reliable records are available for 196 schools. The drive was carried out in two steps: Basic maintenance (M1); and an in-depth followup (M2). Basic maintenance consisted of a certified plumber following a guided checklist and a budget restriction to complete the maintenance (ZAR 5000 at the time of maintenance in December 2017). The guided checklist included ensuring that no leaks occurred in the kitchen, bathrooms, and staff rooms, as well as making sure that all water heaters (boilers or geysers), outside taps and the main stop valve were in working order. An in-depth follow up was carried out at the school as well to assess the work done during M1. The authors used a simple baseline comparison, and reported $28 \%$ reduction in mean MNF within five days after the M1 maintenance campaign.

\section{Analysis technique and metrics}

The objective of this study is to determine the long-term effects of a maintenance campaign on the water usage of a school, and to establish the impact of affluence (the poverty index, the quintile, and the fee-payment) on this response.

The minimum nightly flow (MNF) is the average hourly water usage between 01:00 and 04:00. It is used as an indicator for possible leaks and wastage. This metric has been used in numerous previous studies (Candelieri et al., 2013; Loureiro et al., 2016).

In addition to MNF, the mean daily flow (MDF) metric was used, whcih describes the average hourly water usage per calendar day. This metric was used to avoid large leaks being mistaken for behavioural changes: a large spike in MNF and MDF would indicate a leak.

To determine the lasting effects of the intervention a deviation metric in the MNF and MDF was used to identify outliers and possible leaks calculated by means of Chauvenet's criterion. The statistical theory establishes a probability band from a set of data points that should reasonably contain all the samples of the dataset.

First, the standard score or Z-Score is calculated, defined as:

$$
Z=\frac{x-\mu}{\sigma}
$$


Table 2: Data analysis parameters used during the evaluation.

\begin{tabular}{ll} 
Parameters & Description \\
\hline National EMIS number & School identifier \\
School phase & Primary school or High school \\
Learners & Number of learners in the schools \\
Educators & Number of teachers in the schools \\
Poverty Index & (0-1) poverty level of the school and surrounding area \\
Quintile & (1-5) Classifies schools based on poverty level \\
Fee School & (Yes/No) learners pay school fees \\
Self-Governance School & (S21/S20) Schools pay the municipal bills
\end{tabular}

With $Z$ denoting the number of standard deviations, $\sigma$, the observed value $x$ is above or below the mean value $\mu$.

For the maintenance intervention, a large deviation in MNF would indicate a probable burst. The mean value $\mu_{m}$ is calculated from the past three weeks' MNF usages excluding weekends and school holidays. The period of three weeks was chosen to be long enough to accommodate for single-day usage surges and short enough not to reduce the seasonal effects on usage. A large deviation from the MDF immediately after the intervention would indicate that the usage of the school has returned to its pre-intervention levels.

The probability of the observation being $Z$ standard deviations from the mean is then found using the normal distribution function, denoted $P_{z}$. If the probability of a particular observation's deviation from the mean is less than $\frac{1}{2 n}$ with $n$ being the total number of observations, the particular observation is flagged as an anomaly. If two successive observations are flagged as anomalies, it is assumed that the usage trend has deviated from the norm, and that a burst has occurred or that the school's MDF has returned to its pre-intervention levels.

Table 2 identifies the data and features used during the data analysis process.

\section{RESULTS AND DISCUSSION}

\section{Water usage trends within schools}

Figure 2 (a) and (b) presents the MDF per person at primary schools and high schools, respectively. All quintiles are highlighted, and schools are plotted based on their poverty index. Schools with lower poverty indexes are more affluent, and those with higher poverty indices are more impoverished.

A trend line is presented, showing the line of best fit for the scattered schools. From Figure $2 \mathrm{~b}$ it clear that more affluent high schools use larger amounts of water per person. This is due to several potential factors including more bathrooms at the school; regular watering of the sports grounds; and a higher likelihood of having a hostel (Booysen et al., 2019a). The usage then decreases as the poverty index increases before sharply rising again once the poverty index passes 0.6 for primary schools and 0.7 for high schools. The sharp upward trend distinguishes the boundary of fee paying, and no fee paying 


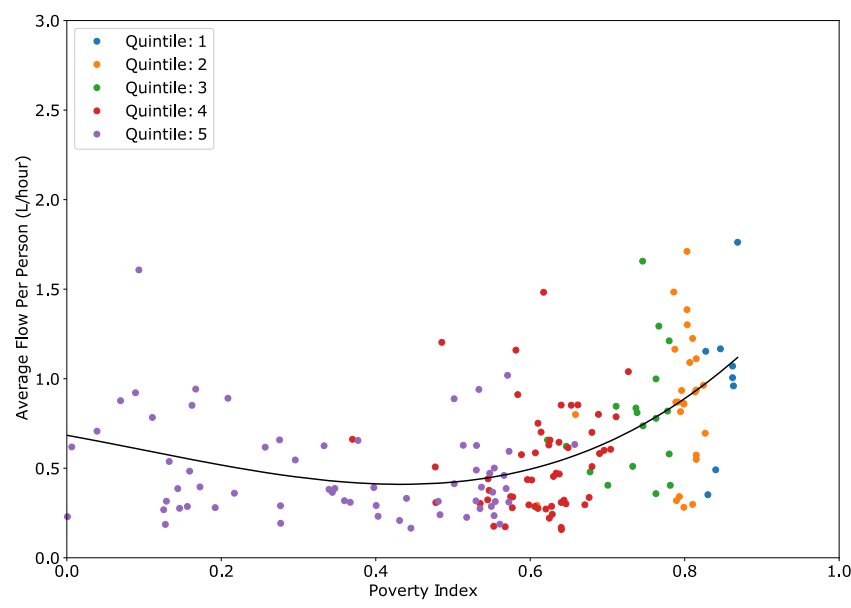

(a) Primary schools

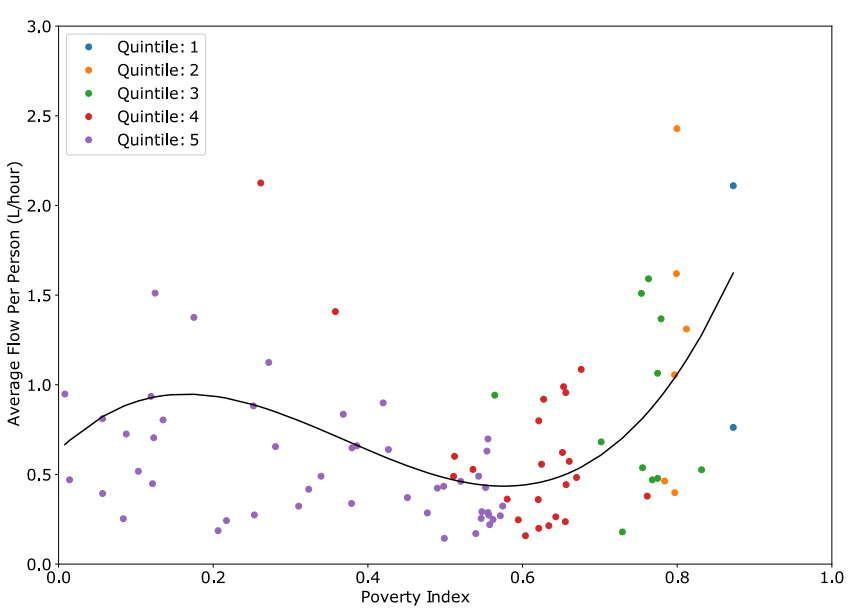

(b) High schools

Figure 2: Mean daily flow (MDF) per person in litre per hour [00:00 - 23:59].

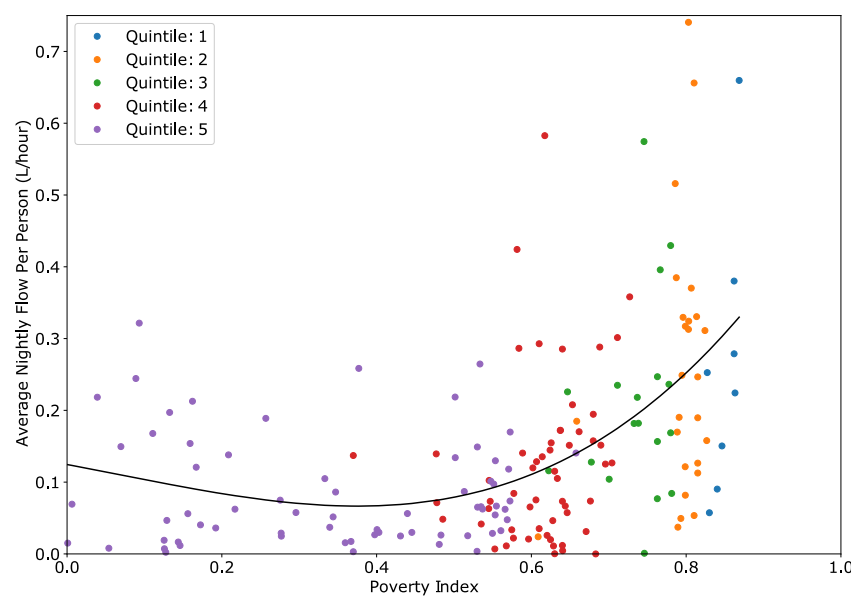

(a) Primary schools

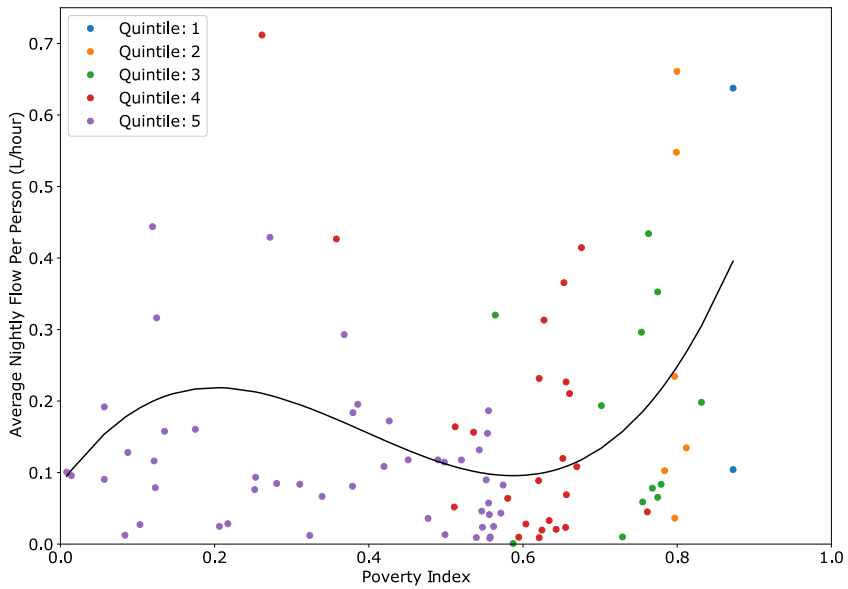

(b) High schools

Figure 3: Minimum nightly flow (MNF) per person in litre per hour [01:00 - 04:00].

schools. No fee paying schools have much smaller maintenance and repair budgets, leading to more frequent leaks and bursts (Booysen et al., 2019a). Moreover, these schools do not pay their own bills, at best breaking the information loop; at worst disabling a good maintenance regime (Samuels et al., 2020). A similar but less pronounced pattern is visible in Figure 2a, which depicts the primary schools.

Figure 3 presents the MNF per person. The shape of the trend line is the same as that of the MDF per person in Figure 2. From these figures it can be deduced that more affluent primary schools use less water than the more affluent high schools. This can be attributed to high schools often housing students on the schools' premises, as well as having a larger number of sports grounds to water during the evenings. Importantly, the MNF, which is a proxy for leaks, is substantially higher at the poorer schools. The figures also show that the water usage per person remains similar for both high schools and primary schools. 
Figure 4 presents the results from the maintenance project for primary and high schools. The MNF is shown and used as a measure of detecting abnormal flow, giving an indication of possible leaks if a large amount of water is used during these hours. The figures present the averaged MNF calculated for the three weeks preceding and immediately after the maintenance, and three weeks precisely one year after the maintenance.

From both figures it can be seen that the maintenance reduced the median MNF for all quintiles at both school types. The averaged improvement in MNF for the three weeks immediately after the maintenance was a $29 \%$ reduction in flow.

The median reductions as percentages and flow rates are given in Table 3 and discussed next.

For the Q2\&3 schools, the median MNF reduced immediately after maintenance by 13\% (from $198 \mathrm{~L} / \mathrm{h}$ ) for the primary schools and by $53 \%$ for the high schools (from $318 \mathrm{~L} / \mathrm{h}$ ). The improvement was substantially more at the high schools, which tend to have bigger infrastructure to maintain. The difference between the mean and median changes at primary schools seen in the distribution, indicates that the reduction was more pronounced at the few heavy users in the top half of the distribution. The high schools' reduction was more equally shared. A year later, at the Q2\&3 primary schools the MNF increased from the baseline at the median school by $26 \%$, indicating an evenly spread net deterioration of the infrastructure over time. That this deterioration was not prevented, could potentially be explained by the subsidence of the "Day Zero" threat, but the same effect is substantially less pronounced at more affluent primary schools, described next. It is therefore more likely to be due to lack of ongoing maintenance and gradual deterioration. At the high schools, the maintenance had a longer lasting impact, resulting in a lasting improvement at the median school of $30 \%$ a year after maintenance.

At the Q4 primary schools, the median school's immediate MNF reduction was $21 \%$ (from $105 \mathrm{~L} / \mathrm{h}$ ) and the mean for all schools was $12 \%$ (from $105 \mathrm{~L} / \mathrm{h}$ ). The difference between these indicates that savings at some "lossy" schools were offset by deterioration at others, evidenced by the increase in the maximum whisker $(+11 \%)$ despite the reduction in the 75 th percentile $(-20 \%)$. At the Q4 high schools, the picture was similar, with immediate reductions in MNF of $29 \%$ (from $105 \mathrm{~L} / \mathrm{h}$ ) at the median school, and a mean reduction of $26 \%$ (from 109L/h) across high schools. Interestingly, the Q4 high schools were more prudent than the primary schools in absolute terms, despite having larger infrastructure. After a year, the median primary school had worsened to an increase in MNF of $23 \%$ from the baseline, similar to the Q2\&3 primary schools At the high schools, the median high school had maintained a 30\% reduction in MNF a year later, again mimicking the Q2\&3 secondary schools.

The Q5 schools managed better to maintain their infrastructure over time, probably due to the availability of disposable funds. After the initial maintenance drive, the MNF at the median primary 


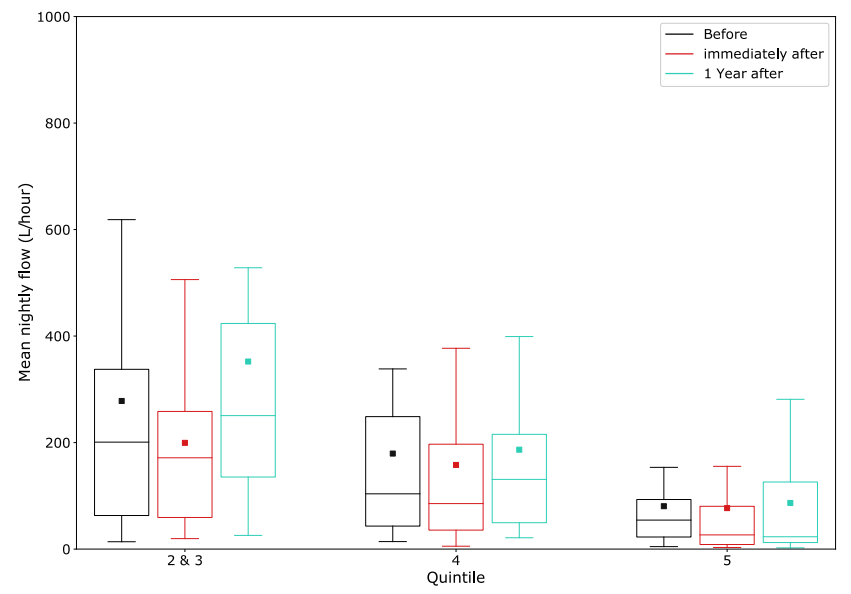

(a) Primary schools

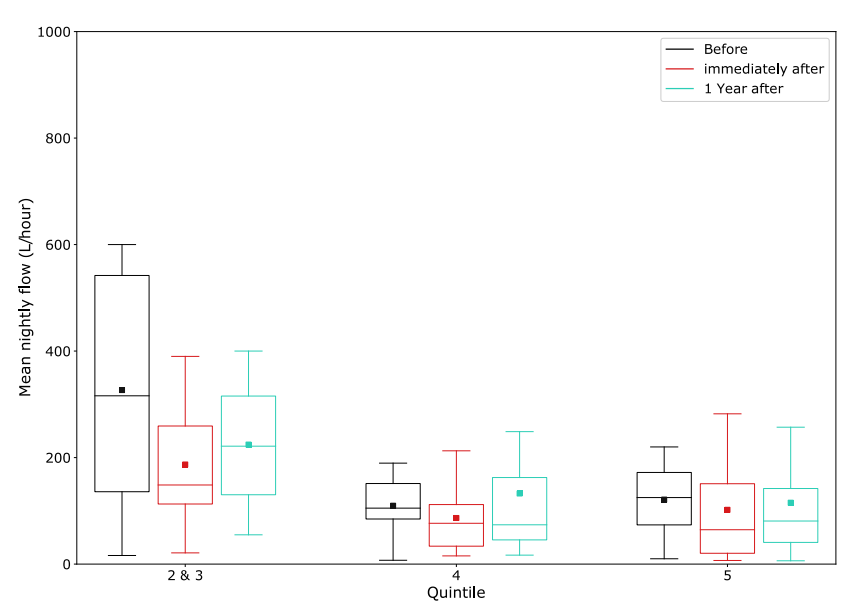

(b) High schools

Figure 4: MNF before, immediately after and one year after maintenance campaign.

Table 3: Reductions as a result of maintenance on MNF at the different schools immediately after and one year after the intervention. The medians are compared as differences in percentage and $\mathrm{L} / \mathrm{h}$.

\begin{tabular}{|c|c|c|c|c|c|c|c|c|c|}
\hline \multirow{2}{*}{\multicolumn{2}{|c|}{ Maintenance change }} & \multirow{3}{*}{$\begin{array}{c}\text { Booysen } \\
\text { et al. } \\
(2019 b) *\end{array}$} & \multicolumn{7}{|c|}{ This paper } \\
\hline & & & \multirow{2}{*}{$\begin{array}{c}\text { Aggre } \\
\text { gate }\end{array}$} & \multicolumn{3}{|c|}{ Primary schools } & \multicolumn{3}{|c|}{ High schools } \\
\hline & & & & Q2\&3 & Q4 & Q5 & Q2\&3 & Q4 & Q5 \\
\hline \multirow{2}{*}{$\operatorname{MNF}[\%]$} & Shortly after & $28 \%$ & $34 \%$ & $13 \%$ & $21 \%$ & $46 \%$ & $53 \%$ & $29 \%$ & $49 \%$ \\
\hline & One year after & - & $21 \%$ & $-26 \%$ & $-23 \%$ & $52 \%$ & $30 \%$ & $30 \%$ & $37 \%$ \\
\hline \multirow[t]{2}{*}{$\mathrm{MNF}[\mathrm{L} / \mathrm{h}]$} & Shortly after & 55 & 46 & 25 & 22 & 24 & 170 & 30 & 62 \\
\hline & One year after & - & 19 & -52 & -24 & 27 & 96 & 31 & 47 \\
\hline
\end{tabular}

* The results reported by Booysen et al. (2019b) were based on a mean reduction, and used only a week before and a week after maintenance. This paper used three weeks prior, three weeks subsequent to maintenance, and three weeks a year later. The results are therefore not directly comparable and only given as a reference.

Table 4: Longevity of the maintenance performed at schools. Percentage of schools in each category.

\begin{tabular}{c|cccccc} 
& \multicolumn{3}{|c}{ Primary schools } & \multicolumn{3}{c}{ High schools } \\
& Q2\&3 & Q4 & Q5 & Q2\&3 & Q4 & Q5 \\
\hline No improvement & $30 \%$ & $33 \%$ & $30 \%$ & $14 \%$ & $9 \%$ & $45 \%$ \\
Short-term improvement & $23 \%$ & $33 \%$ & $30 \%$ & $43 \%$ & $36 \%$ & $15 \%$ \\
Long-term improvement & $47 \%$ & $33 \%$ & $40 \%$ & $43 \%$ & $55 \%$ & $40 \%$
\end{tabular}

school was $46 \%$ (from $52 \mathrm{~L} / \mathrm{h}$ ), but the mean reduction across schools was a mere $3 \%$ (from $76 \mathrm{~L} / \mathrm{h}$ ). This indicates that maintenance at the affluent schools, on average, was already in a better state than at the poor schools. At these low levels of MNF, a newly sprung leak at one or two schools can diminish the collective benefit. At the Q5 high schools, the median school reduced their MNF by 49\% (from $126 \mathrm{~L} / \mathrm{h}$ ). However, since the baseline is low, the $49 \%$ saved at the median school is small in comparison with the large volumes saved at the poorer schools. After a year, the median primary school managed to improve their MNF even further, with a reduction of 52\% from the baseline. A year later, the affluent high schools managed to maintain a $7 \%$ reduction on average, with the median school maintaining $37 \%$ reduction from the baseline.

Interestingly, when the median primary schools for each of the quintile groupings are considered, the flow rate reductions after immediate maintenance were very similar but from very different baselines: 25L/h, 22L/h, and 24L/h, for Q2\&3, Q4, and Q5, respectively. After the year, the change in absolute 
MNF was in the opposite direction. A year later, the median Q2\&3 school had increased their MNF by $52 \mathrm{~L} / \mathrm{h}$ compared to the original baseline. This is a stark difference when compared to the other quintiles a year on: the median Q4 school lost 24L/h more than the baseline, with the mean fairly stable at 5L/h more. At the Q5 schools, the median school actually improved further, as we saw earlier.

These results seem to indicate that money is best spent at the Q2\&3 schools, but that the impact is lasting at the high schools, while the primary schools need continuing maintenance to secure the gains.

In order to further assess the long-term effectiveness of the maintenance, the technique described in Section 3.4 was used. If no improvement in MNF was recorded immediately following the maintenance, it was assumed that no leaks were present. If a school's MNF was flagged as an anomaly for successive days, it was assumed that a burst or leak had occurred. If a leak was present within three months from the date of maintenance, the intervention was classified as a short-term improvement. If an event was not detected within three months the intervention was classified as a long-term improvement. Table 4 presents the improvement timelines for the maintenance performed at the schools. The results show that in all cases that an improvement was registered, at least half of the schools had a long-term improvement. A third or more of the schools had a long-term improvement, with $47 \%$ of Q2\&3 primary schools still showing improvements after a year, and 55\% of Q4 secondary schools still showing improvements after a year.

\section{CONCLUSION}

Water sustains life, and nowhere is our dependence on it clearer than in large cities in drought-stricken areas. In this paper we assessed the impact of a maintenance campaign that was performed during Cape Town's "Day Zero" drought. In addition to the existing research on the topic, we evaluate the impact of affluence on the response to the campaigns, and also gauged the long-term impact of the campaigns.

The results showed a strong correlation between the poverty index of the school and the amount of water used. Affluent schools used more than the median schools, and the poorer schools using a lot more, showing some resemblance to a U-curve. This trend was visible for the whole day as well as for midnight hours. The affluent schools probably use more due to larger and more facilities, and price insensitivity; the median schools use less because of price sensitivity with sufficient finances to maintain the plumbing; while the poorer schools probably use most because of an information asymmetry and lack of funds to keep up maintenance.

The maintenance results showed that maintenance had the biggest immediate impact on the poorer schools, with both the median and mean school's usage dropping substantially. However, the gains were not long-lasting for most poor schools, with only $47 \%$ of poor primary schools and $44 \%$ of poor high schools still benefiting a year later. 
An important factor to take into consideration, however, is that the urge to improve maintenance is constricted by the availability of mostly financial resources.

The Q4 schools are in the precarious position that they receive fewer grants from government than the poorer Q2\&3 schools, but also have less financial resources than the more affluent Q5 schools, despite having to maintain substantial infrastructure. After the initial behavioural campaign, all the schools in the project were given access to the online smart metering platform, and were sent weekly reports. Moreover, the Cape Town Council had increased their tariffs and these would have finally found their way onto the bills.

\section{ACKNOWLEDGEMENTS}

The authors would like to extend their sincere gratitude to the many corporate, academic and governmental parties that made this project, www.schoolswater.co.za, and the research possible. We would like to extend a special word of gratitude to Shoprite, Cape Talk, the Western Cape Education Department, the Office of the Premier, the Water Research Commission, Bridgiot, InnovUS, MTN, Stellenbosch University, and our collaborators at the University of Cape Town.

\section{REFERENCES}

Adamowski, J., Fung Chan, H., Prasher, S.O., Ozga-Zielinski, B., Sliusarieva, A., 2012.

Comparison of multiple linear and nonlinear regression, autoregressive integrated moving average, artificial neural network, and wavelet artificial neural network methods for urban water demand forecasting in Montreal, Canada. Water Resources Research 48. DOI:

\section{$\underline{10.1029 / 2010 \mathrm{WR} 009945 .}$}

Baudoin, M.A., Vogel, C., Nortje, K., Naik, M., 2017. Living with drought in South Africa: Lessons learnt from the recent El Niño drought period. International Journal of Disaster Risk Reduction 23, 128 - 137. DOI: $\underline{10.1016 / j . i j d r r .2017 .05 .005 .}$

Van der Berg, S., 2009. Fiscal incidence of social spending in South Africa, 2006. A report to National Treasury, 28 February 2009.

Van der Berg, S., Burger, C., Burger, R., de Vos, M., du Rand, G., Gustafsson, M., Moses, E., Shepherd, D.L., Spaull, N., Taylor, S., et al., 2011. Low quality education as a poverty trap. Stellenbosch Economic Working Papers No.25/2011. Initially a synthesis report to PSPPD, Available at SSRN: DOI: 10.2139/ssrn.2973766

Booysen, M., Wijesiri, B., Ripunda, C., Goonetilleke, A., 2019a. Fees and governance: Towards sustainability in water resources management at schools in post-apartheid South Africa.

Sustainable Cities and Society 51, 101694. DOI: 10.1016/j.scs.2019.101694. 
Booysen, M.J., Ripunda, C., Visser, M., 2019b. Results from a water-saving maintenance campaign at Cape Town schools in the run-up to day zero DOI: $10.31224 /$ osf.io/45cf9.

Bougadis, J., Adamowski, K., Diduch, R., 2005. Short-term municipal water demand forecasting. Hydrological Processes 19, 137-148. DOI: 10.1002/hyp.5763.

Bueno, D.C., 2019. Energy and water conservations at school setting towards sustainable environment. Institutional Multidisciplinary Research and Development Journal (IMRaD Journal) 2.

Candelieri, A., Archetti, F., Messina, E., 2013. Improving leakage management in urban water distribution networks through data analytics and hydraulic simulation. WIT Transactions on Ecology and the Environment 171, 107-117.

Donnenfeld, Z., Crookes, C., Hedden, S., 2018. A delicate balance water scarcity in South Africa. https: //issafrica.s3.amazonaws.com/site/uploads/sar13-2.pdf. Accessed on 2020-04-12.

Engelbrecht, J., Harding, A., 2008. The impact of the transition to outcomes-based teaching on university preparedness in mathematics in South Africa. Mathematics Education Research Journal 20, 57-70.

Enqvist, J.P., Ziervogel, G., 2019. Water governance and justice in Cape Town: An overview. WIREs Water 6, e1354. DOI: 10.1002/wat2. 1354,

Gallego Sanchez-Torija, J., Larrumbide, E., Bedoya, C., 2017. The incorporation of the study into water consumption in energy audits in schools. Revista de la construcci'on 16, 361-373. DOI: $\underline{10.7764 / R D L C .16 .3 .361 . ~}$

Ghiassi, M., Zimbra, D.K., Saidane, H., 2008. Urban water demand forecasting with a dynamic artificial neural network model. Journal of Water Resources Planning and Management 134, 138-146. DOI: 10.1061/ (ASCE)0733-9496(2008)134:2(138).

Lomofsky, L., Lazarus, S., 2001. South africa: First steps in the development of an inclusive education system. Cambridge Journal of education 31, 303-317.

Loureiro, D., Amado, C., Martins, A., Vitorino, D., Mamade, A., Coelho, S.T., 2016. Water distribution systems flow monitoring and anomalous event detection: A practical approach. Urban Water Journal 13, 242-252. DOI: 10.1080/1573062X.2014.

McLaren, D., 2017. Funding basic education. http://section27.org.za/wp-content/uploads/2017/02/ Chapter-2.pdf. Accessed on 2020-03-02.

Middlestadt, S., Grieser, M., Hern'andez, O., Tubaishat, K., Sanchack, J., Southwell, B., Schwartz, 
R., 2010. Turning minds on and faucets off: Water conservation education in jordanian schools. The Journal of Environmental Education 32, 37-45. DOI: 10.1080/00958960109599136.

Nhlapo, V.A., 2009. A whole-school approach to facilities maintenance. Ph.D. thesis. North-West University.

Ren, Z., Li, S., 2016. Short-term demand forecasting for distributed water supply networks: A multi-scale approach, in: 2016 12th World Congress on Intelligent Control and Automation (WCICA), pp. 1860-1865.

Samuels, J., Grobbelaar, S., Booysen, M., 2020. Light-years apart: Energy usage by schools across the South African affluence divide. Energy Research \& Social Science 70, 101692. DOI:

$\underline{10.1016 / \text { j.erss.2020.101692. }}$

Spaull, N., 2019. Priorities for education reform in South Africa.

https://nicspaull.files.wordpress.com/2019/01/spaull-priorities-for-educ-reform-treasury-19-jan2019.pdf. Accessed on 2020-04-24.

Still, D., Bhagwan, J., 2008. The status and use of potable water conservation and savings devices in the domestic and commercial environments in South Africa, in: Water Distribution Systems Analysis 2008, pp. 1-11.

Tarbet, A.J., Svensson, R., Gilley, R.L., Tang, S., 2006. Water conservation in Windhoek schools.

Visser, M., Booysen, M.J., Berger, K., Brühl, J., 2021. Saving water at Cape Town schools by using smart metering and behavioural change. Water Resources and Economics, volume 34, 2021.

DOI: $10.1016 /$ j.wre.2020.100175.

WCED, 2019. Western Cape Government Education budget vote 2019/2020.

https://www.westerncape.gov. za/news/western-cape-government-education-budget-vote-20192020. Accessed on 2020-04-12.

WCG, 2020. Western Cape Government, Estimates of provincial revenue and expenditure.

https://www.westerncape.gov.za/provincial-

treasury/files/atoms/files/Estimates $\% 20$ of $\% 20$ Provincial $\% 20$ Revenue $\%$

20and\%20Expenditure\%202020.pdf. Accessed on 2020-05-02.

WHO, 2019. Drinking-water. https://www.who.int/news-room/fact-sheets/detail/drinking-water. Accessed on 2020-04-02.

Xaba, M.I., 2012. A qualitative analysis of facilities maintenance - a school governance function in South Africa. South African Journal of Education 32, 215 - 226. URL:

$\underline{\text { http://www.scielo.org.za/scielo. php?script=sci arttext\&pid }=\text { S0256- }}$ 
$01002012000200008 \& n r m=$ iso.

Xiong, Y.J., Hao, X.R., Liao, C., Zeng, Z.N., 2016. Relationship between water-conservation behavior and water education in Guangzhou, China. Environmental Earth Sciences 75, 1. 